\title{
ESTRATÉGIAS ORGANIZACIONAIS NO CONTEXTO DA AVALIAÇÃO DA PÓS-GRADUAÇÃO BRASILEIRA
}

(D) LUCI MARI APARECIDA RODRIGUES'

(D) KATIA DENISE MOREIRA"

(D) CIBELE BARSALINI MARTINS"I

\begin{abstract}
Universidade Federal de Santa Catarina (UFSC), campus Reitor João David Ferreira Lima, Florianópolis-SC, Brasil; Iuci.mari@ufsc.br

Universidade Federal de Santa Catarina (UFSC), campus Reitor João David Ferreira Lima, Florianópolis-SC, Brasil; katia.denise@ufsc.br

II Universidade Federal de Santa Catarina (UFSC), campus Reitor João David Ferreira Lima, Florianópolis-SC, Brasil; cibele.martins@ufsc.br
\end{abstract}

\section{RESUMO}

Esta pesquisa identifica estratégias de um Programa de Pós-Graduação em Administração de uma universidade federal para atender ao Sistema de Avaliação da Pós-graduação no Brasil. Os dados foram coletados em documentos e entrevistas com integrantes da gestão do Programa no quadriênio de avaliação 2013-2016. A partir da elucidação das estratégias vigentes, descreveu-se a dimensão teórica da gestão estratégica que contemplou as ações que materializaram o processo de sua formação e implementação. Constatou-se fragilidades quanto aos indicadores Corpo Docente e Inserção Social e predominância de estratégias deliberadas, indicando o caráter coercitivo da avaliação sobre a gestão estratégica do Programa. Concluiu-se que uma revisão do processo estratégico, em diálogo com os agentes sociais que compõem o Programa, poderá colaborar para melhores resultados no sistema de avaliação.

PALAVRAS-CHAVE DESENVOLVIMENTO ORGANIZACIONAL • EDUCAÇÃo SUPERIOR • AVALIAÇÃO DA PÓS-GRADUAÇÃO. 


\section{ESTRATEGIAS ORGANIZACIONALES EN EL CONTEXTO DE LA EVALUACIÓN DE LA POSGRADUACIÓN BRASILEÑA}

\section{RESUMEN}

Esta investigación identifica las estrategias de un Programa de Posgraduación en Administración de una universidad federal para atender al Sistema de Evaluación de la Posgraduación en Brasil. Los datos fueron recolectados en documentos y entrevistas con integrantes de la gestión del Programa en el cuadrienio de evaluación 2013-2016. A partir de la elucidación de las estrategias vigentes, se describió la dimensión teórica de la gestión estratégica que consideró las acciones que materializaron el proceso de su formación e implementación. Se constataron fragilidades cuanto a los indicadores Cuerpo Docente e Inserción Social y predominancia de estrategias deliberadas, indicando el carácter coercitivo de la evaluación sobre la gestión estratégica del Programa. Se concluyó que una revisión del proceso estratégico, en diálogo con los agentes sociales que componen el Programa, podrá colaborar para obtener mejores resultados en el sistema de evaluación.

PALABRAS CLAVE DESARROLLO ORGANIZACIONAL・EDUCACIÓN SUPERIOR • EVALUACIÓN DE LA POSGRADUACIÓN.

\section{ORGANIZATIONAL STRATEGIES IN THE CONTEXT OF EVALUATION OF BRAZILIAN GRADUATE STUDY}

\section{ABSTRACT}

This study identifies strategies used in a graduate program in Administration, at a federal university, to meet the requirements of the Graduate Evaluation System in Brazil. Data were collected from documents and interviews with members of the program's management, in the 2013-2016 quadrennial evaluation. Based on the current strategies, the theoretical dimension of strategic management was described, which included the actions that established the process of its formation and implementation. Weaknesses were observed in relation to the Teaching Staff and Social Insertion indicators, as well as the predominance of deliberate strategies, indicating the coercive nature of the evaluation on the strategic management of the program. It was concluded that a review of the strategic process, in dialogue with the social agents that make up the program, could help achieve better results in the evaluation system. 


\section{INTRODUÇÃO}

As universidades viabilizam os alicerces para o processo de criação e disseminação do saber, o qual promove a geração de capital científico e tecnológico (BRASIL, 2010; MACCARI et al., 2009). Nesse contexto, ao se considerar que as políticas de educação contemplam a avaliação externa do ensino superior, a ênfase deste estudo recai sobre os sistemas de avaliação da pós-graduação stricto sensu, que se caracterizam como relevantes para a gestão estratégica das instituições de ensino e auxiliam no estabelecimento de outras políticas e ações direcionadas a fomentar o avanço da ciência nos países (HOUSE, 1992; MAGGI; PAREDES, 2017).

Diante do exposto, volta-se à realidade do Brasil, na qual o Sistema de Avaliação da Pós-Graduação é gerenciado pela Coordenação de Aperfeiçoamento de Pessoal de Nível Superior (Capes), agência que ampliou a credibilidade e a legitimidade desse sistema, tornando-o referência em nível internacional (BRASIL, 2008, 2010; MACHADO-DA-SILVA, 2003; MARTINS et al., 2012; OLIVEIRA; ALMEIDA, 2011; VOGEL; KOBASHI, 2015). Dessa forma, ao se considerar que os programas de pós-graduação têm um papel essencial na disseminação do conhecimento para a sociedade e que sua atuação é impactada pelo Sistema de Avaliação da Capes, por meio da mensuração de desempenho e do fomento a tais programas (BRASIL, 2010; MORITZ; MORITZ; MELO, 2011), busca-se a compreensão de como as estratégias de um programa de pós-graduação de uma universidade federal podem contribuir ao atendimento daquilo que estabelecem as normas e diretrizes do sistema quanto à sustentabilidade e expansão do programa.

Nessa direção, destaca-se que o tema da avaliação externa da educação superior tem sido abordado na literatura a partir de dimensões que tratam da descrição de sistemas de avaliação, aspectos relacionados à sua qualidade ao seu impacto no crescimento das nações, dada a necessidade permanente de atendimento de demandas sociais, tecnológicas e econômicas (FUENTES, 2016; HOUSE, 1992; MAGGI; PAREDES, 2017; VAN DAMME, 2000; VILLANUEVA, 2004). No contexto das pesquisas brasileiras, tais temáticas são contempladas em relação aos aspectos históricos, evolução e fragilidades constatadas (CORRÊA et al., 2017).

No que se refere ao Sistema de Avaliação da Pós-Graduação nacional, há trabalhos sobre a necessidade de se considerar a internacionalização dos programas, o impacto do sistema na produção científica, críticas voltadas à forma como ele é organizado e como os programas são avaliados, além de estratégias e modelagens alternativas a tal sistema (CORRÊA et al., 2017; VOGEL; KOBASHI, 2015).

Considerado esse panorama, percebeu-se que havia espaço para se investigar a temática estabelecida em termos de alinhamento à teoria da estratégia, visto sua difusão ainda incipiente na avaliação de programas de pós-graduação no Brasil (MARTINS; MACCARI, 2015). Ou seja, se existe uma política nacional de educação 
que é gerida e aplicada, entre outros mecanismos, por meio de um sistema de avaliação da pós-graduação, é salutar reconhecer que atender às exigências e diretrizes nele dispostas possa ser estratégico para os programas que pretendam se manter credenciados e, ainda, ampliar recursos financeiros. Isso porque cabe à Capes, por meio desse sistema, proceder quanto ao estabelecimento de diretrizes de funcionamento, creditação e distribuição de recursos aos programas avaliados (BRASIL, 2008).

A partir disso, o objetivo deste estudo é identificar estratégias relacionadas a atender ao Sistema de Avaliação da Pós-Graduação brasileira em um programa de pós-graduação em Administração de uma universidade federal. Selecionou-se, então, de modo intencional, o Programa de Pós-Graduação em Administração (PPGA) da Universidade Federal de Santa Catarina (UFSC) por sua representatividade no contexto regional catarinense e, ainda, pelo interesse intrínseco de pesquisa sobre os esforços que o referido programa tem feito para ampliar seus resultados no Sistema de Avaliação ora apresentado (BRASIL, 2015).

Ou seja, busca-se investigar elementos e visões de atores sociais situados em uma realidade específica, de maneira que ela possa ser profundamente investigada e compreendida sob dimensões teóricas selecionadas pelos pesquisadores e sem compromisso com generalizações, sob a égide do que pressupõe uma abordagem de natureza qualitativa de descrição e compreensão da realidade pesquisada.

No que se refere à oportunidade e à relevância desta pesquisa, considerou-se o cenário contemporâneo do Brasil, no qual medidas econômicas de austeridade foram recentemente aplicadas em todas as áreas, diminuindo o montante de repasses financeiros às universidades, e, consequentemente, repercutiram na produção científica nacional, que se materializa pela gestão estratégica dos programas de pós-graduação (ANGELO, 2016).

Ademais, as universidades que comportam os programas de pós-graduação estão inseridas em contextos locais e regionais distintos, com características e demandas peculiares, e não há uma padronização de infraestrutura física e de gestão financeira ou mesmo de fontes complementares de recursos (MARTINS; MACCARI, 2015), o que leva à suposição de que determinados programas de pós-graduação sofram mais impactos do que outros durante períodos de crise e, com base nessa conjuntura, tenham que rever suas estratégias de gestão para se manterem credenciados ao Sistema de Avaliação da Capes.

Diante disso, faz-se relevante investigar de que maneira a utilização de estratégias, sejam elas deliberadas ou emergentes (MINTZBERG; WATERS, 1985), sob a égide de um processo integrativo de gestão estratégica (BALBASTRE-BENAVENT; CANET-GINER, 2011), pode colaborar em termos de respostas para a minimização dos impactos de tal quadro restritivo, ao mesmo tempo em que se estabelece uma 
perspectiva de posterior ampliação das discussões sobre o tema abordado, conforme disposto nas considerações finais deste estudo.

Vale destacar que a concepção da estratégia adotada nesta pesquisa baseia-se no que foi proposto por Mintzberg, Ahlstrand e Lampel (1998) e por Andersen (2013), que entendem que a estratégia se relaciona às organizações e seu entorno. A partir disso, dentre as tipologias da estratégia, optou-se pela teorização proposta por Mintzberg e Waters (1985), na qual são abordados os processos de formação e de implementação de estratégias, que contemplam ações planejadas (deliberadas) pela gestão superior, bem como aquelas que possuem padrões de ação que se desenvolvem sem uma intenção preestabelecida (emergentes).

Em termos estruturais, este artigo se inicia com esta introdução, na qual o tema é apresentado, bem como a problemática dele decorrente. Dela, passa-se ao objetivo do estudo e sua justificativa. Na segunda seção, trata-se da teorização sobre estratégia, partindo-se de suas origens, com foco na tipologia estratégica de Mintzberg e Waters (1985), bem como da inserção da teoria da estratégia nas universidades. Ademais, faz-se uma caracterização do Sistema de Avaliação da Pós-Graduação vigente no Brasil. Em seguida, são trazidos os métodos adotados e, depois, apresentados os dados e os resultados relativos ao fenômeno em questão, sob a perspectiva dos padrões de estratégias descritos na tipologia já citada, para então seguir à seção das considerações finais e às referências.

\section{ESTRATÉGIA}

O termo "estratégia”, proveniente da palavra grega strategos, apresenta registros históricos que demonstram sua utilização por líderes militares, tais como César, Sun Tzu e Maquiavel (KOTLER; BERGER; BICKHOFF, 2010; LUECKE, 2009; QUINN, 1978). Influenciado pelo uso na arte militar, o termo "estratégia" foi inserido no contexto organizacional na década de 1930, mas sem grandes repercussões (MINTZBERG; QUINN, 2001).

Dentre as contribuições sobre o tema, destacam-se as de Barnard (1938), que abordou as funções executivas a partir de sistemas cooperativos, em que o fator estratégico foi colocado como necessário ao processo decisório e, ainda, como fator limitante no que se refere ao controle, local e tempo corretos para o atendimento de propósitos estabelecidos.

Posteriormente, na década de 1950, a estratégia foi associada à gestão propriamente dita, o que impulsionou pesquisas na área e a incorporação da disciplina intitulada "Business Policy" às escolas de administração (RONDA-PUPO; GUERRAS-MARTIN, 2012). Desde então, a literatura sobre estratégia tem se ampliado (BHALLA et al., 2009; OVERED, 1983) por meio de variadas perspectivas e abordagens. 
As concepções de estratégia são múltiplas. Tal fato revela que não há um consenso sobre elas, porque envolvem uma ampla e complexa gama de dimensões de interpretação e aplicação (ANSOFF, 1965; KOTLER; BERGER; BICKHOFF, 2010; MINTZBERG, 1987; MINTZBERG; AHLSTRAND; LAMPEL, 1998). Com base nisso, são trazidos, no Quadro 1, exemplos dessas definições alinhados aos propósitos deste estudo.

QUADRO 1 - Conceitos de estratégia

\begin{tabular}{|l|l|l|}
\hline AUTOR & OBRA & CONCEITO ABORDADO \\
\hline BARNARD (1938) & $\begin{array}{l}\text { The functions of the } \\
\text { executive }\end{array}$ & $\begin{array}{l}\text { "Ação pessoal ou da organização como elemento crucial na } \\
\text { tomada de decisão, que envolve todo o esforço intencional } \\
\text { para atender a um propósito"' (p. 203, tradução nossa). }\end{array}$ \\
\hline ANSOFF (1965) & $\begin{array}{l}\text { Corporate strategy: } \\
\text { an analytic approach } \\
\text { to business policy for } \\
\text { growth and expansion }\end{array}$ & $\begin{array}{l}\text { Conceituou a estratégia a partir do elo comum entre produtos } \\
\text { e mercados, sob uma orientação de desempenho voltada ao } \\
\text { ambiente externo. A partir disso, o autor define a estratégia } \\
\text { com base nos seguintes elementos: conjunto de produtos e } \\
\text { mercados, vetor de crescimento, vantagem competitiva e } \\
\text { sinergia. }\end{array}$ \\
\hline PORTER (1980) & $\begin{array}{l}\text { Competitive strategy: } \\
\text { techniques for } \\
\text { analyzing industries } \\
\text { and competitors }\end{array}$ & $\begin{array}{l}\text { Trata-se do desenvolvimento de uma formulação ampla, para } \\
\text { definir como uma empresa competirá, quais devem ser suas } \\
\text { metas e quais políticas serão necessárias para alcançá-las. }\end{array}$ \\
\hline $\begin{array}{l}\text { MINTZBERG, } \\
\text { AHLSTRAND e } \\
\text { LAMPEL (1998) }\end{array}$ & $\begin{array}{l}\text { Strategy safari: a } \\
\text { guided tour through } \\
\text { the wilds of strategic } \\
\text { management }\end{array}$ & $\begin{array}{l}\text { Força mediadora entre a organização e o seu meio envolvente, } \\
\text { centrando-se nas decisões e ações que surgem naturalmente. } \\
\text { formação da estratégia não se limita aos processos } \\
\text { intencionais, mas pode ocorrer como um padrão de ações } \\
\text { formalizadas ou não. }\end{array}$ \\
\hline ANDERSEN (2013) & $\begin{array}{l}\text { Short introduction to } \\
\text { strategic management }\end{array}$ & $\begin{array}{l}\text { O resultado de um processo de formação que integra a } \\
\text { interação deliberada (top-down), emergente (bottom-up) e a } \\
\text { interas atores envolvidos. }\end{array}$ \\
\hline
\end{tabular}

Fonte: Adaptado de Bulgacov et al. (2007), Mainardes, Ferreira e Tontini (2009).

Conforme disposto no Quadro 1, a estratégia é relevante nas organizações, por considerar as formas de alocação e utilização de recursos, bem como a busca na melhoria dos modos gerenciais e produtivos, sob uma perspectiva de ampliação na eficiência, expansão estrutural, competitividade e conquista de novos mercados (ANSOFF, 1965; CHANDLER, 1962; PORTER, 1980).

Enquanto objeto de estudo, a estratégia organizacional abrange tanto o conteúdo, que se relaciona às decisões e ações, quanto o processo, o qual abrange a maneira como tais decisões e ações ocorrem (BARNES, 2002). Assim, dentre os diversos temas de interesse da estratégia, tem-se os voltados à estrutura, às racionalidades, aos mercados, ao envolvimento dos atores, às escolhas, aos processos (tanto de formação como de implementação), a recursos e capacidades, às alianças, entre outros aspectos ligados ao contexto organizacional (ANDERSEN,

1 Do original: "personal or organizational action is the crucial element, as it ultimately is in all purposite effort, the word 'strategy' is preferible". 
2004; CHANDLER, 1962; HART, 1992; MINTZBERG; AHLSTRAND; LAMPEL, 1998; MINTZBERG; LAMPEL, 1999; MINTZBERG; WATERS, 1985; PORTER, 1980; RING; DOZ; OLK, 2005; WHITTINGTON, 2002).

Vale ressaltar que, embora a perspectiva clássica da estratégia tenha proporcionado avanços para o campo da gestão, especialmente no tocante ao desenvolvimento de ferramentas - a análise SWOT (Forças, Fraquezas, Oportunidades e Ameaças, em inglês Strengths, Weaknesses, Opportunities and Threats), o Balanced Scorecard, as aplicações da Matriz Boston Consulting Group (BCG), a análise das Cinco Forças de Porter, o Planejamento Estratégico, as Competências Essenciais (Core Competences), entre outros (QEHAJA; KUTLLOVCI; PULA, 2017; VOLBERDA, 2004) -, a aplicabilidade de determinados preceitos difundidos foi questionada.

Nessa direção, a perspectiva moderna da estratégia, que se alinha aos propósitos deste estudo, busca superar tais pontos de tensão, caracterizando-se como descritiva, porque contempla uma estrutura como referência para se considerar como as estratégias precisam estar relacionadas aos padrões de comportamento reais das organizações, seja nas fases de formação, seja de implementação (MINTZBERG; QUINN, 1998; VOLBERDA, 2004). Então, sob uma égide adaptativa entre ações e metas, todos os atores organizacionais desempenham atividades relacionadas e que impactam no curso das estratégias (ANDERSEN, 2000; HENSMANS, 2003), as quais assumem padrões e se mostram cruciais para o processo de aprendizado e evolução global das instituições em seus ambientes (interno e externo) (FARJOUN, 2002; MINTZBERG; WATERS, 1985; QUINN, 1978). A seguir, trata-se das tipologias da estratégia.

\section{Tipologias da estratégia: o trabalho de Mintzberg e Waters (1985)}

Destaca-se que inúmeros trabalhos contemplam as tipologias da estratégia em um contexto de gestão estratégica (FLOYD; WOOLDRIDGE, 1997; HART, 1992; MINTZBERG; AHLSTRAND; LAMPEL, 1998; MINTZBERG; WATERS, 1985; NONAKA, 1988; PORTER, 1980, 2008; WHITTINGTON, 1996). Nesse sentido, aborda-se neste estudo a proposta de Mintzberg e Waters (1985), na qual os autores definem dois tipos de estratégia: "deliberada" e "emergente".

Mintzberg e Waters (1985) argumentam que o estudo acerca dos fluxos de decisões organizacionais, nos quais as estratégias poderiam ser identificadas como padrões ou consistências que se formam dentro deles, viabilizaria a investigação sobre a origem de tais estratégias. Diante disso, o foco recairia na relação entre planos de liderança e intenções e sobre o que as organizações efetivamente fizeram. Ao considerar ambos os fenômenos, Mintzberg e Waters (1985) utilizaram o rótulo de estratégia e nomearam, respectivamente, um como "pretendido", e o outro como "realizado". Ademais, ao realizarem uma comparação entre estratégia 
pretendida e estratégia realizada, os autores distinguiram estratégias deliberadas de emergentes, conforme os tipos apresentados na Figura 1.

FIGURA 1 - Tipos de estratégia

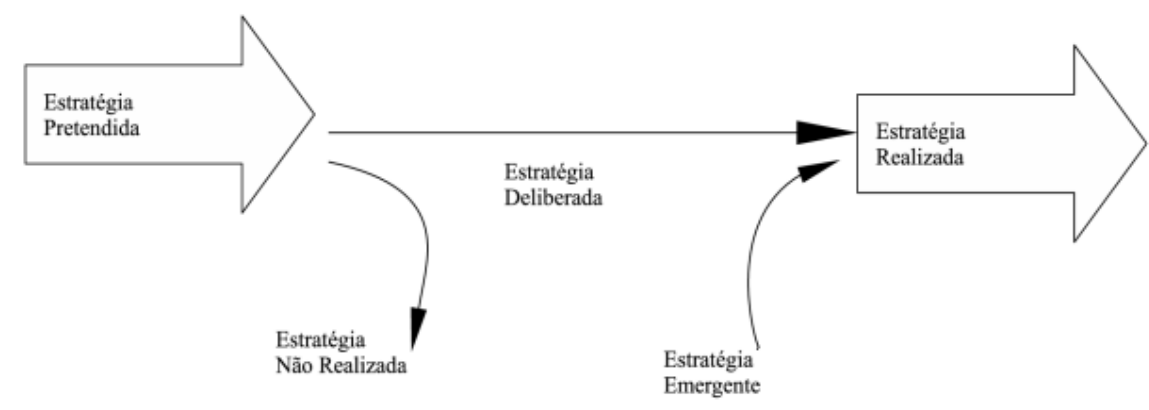

Fonte: Mintzberg e Waters (1985, p. 258).

Conforme o exposto na Figura 1, baseada na visão de Mintzberg e Waters (1985), a diferença fundamental entre a estratégia deliberada e a emergente é que a primeira se preocupa com a direção e o controle, enquanto a segunda abre possibilidades para o que os autores chamam de "aprendizado de estratégia”. No entanto, essa última não deve ser entendida como sinônimo de caos, mas sim como um tipo de ordem não intencional.

Adicionalmente, ao comentarem a estratégia emergente, Mintzberg e Waters (1985) ressaltam que, assim como as estratégias puramente deliberadas, é difícil imaginar ações organizacionais desprovidas de intenção, mesmo em circunstâncias em que certos padrões sejam impostos diretamente pelo ambiente à organização. Nesse sentido, tanto as estratégias deliberadas como as emergentes constituem polos de um contínuo (MINTZBERG; WATERS, 1985). São combinados estados e dimensões que afetam o trabalho da estratégia, por meio de intenções com maior ou menor grau de precisão, compartilhamento, controle e explicitação, gestão de consenso, continuidade com o passado e orientação para mudanças futuras em face de ambientes que oscilam em níveis altos e baixos, favorabilidade, controlabilidade e previsibilidade (HAX; MAJLUF, 1988).

Destarte, o trabalho de Mintzberg e Waters (1985) integra uma linha de estudos que busca compreender como de fato a estratégia surge, com foco no processo estratégico (SMINIA, 2009). Pesquisas realizadas após o trabalho dos autores indicaram que a visão apenas de conteúdo estratégico (planejada, racional) não contempla a gama de desafios que se apresentam para as organizações, de modo que as estratégias são formadas e implementadas por meio de um processo complexo, que abrange todos os níveis organizacionais (MINTZBERG; LAMPEL, 1999; RIALP-CRIADO; GALVÁN-SÁNCHEZ; SUÁREZ-ORTEGA, 2010; SMINIA, 2009). 
Nessa direção, o processo de formação de estratégia, em uma perspectiva integrativa (LAVARDA; GINER; BONET, 2011), pode ser caracterizado pela aplicação simultânea de racionalidade e emergência, englobando conjuntamente formulação e implementação, em todos os níveis organizacionais (BALBASTRE-BENAVENT; CANET-GINER, 2011; KIM; STING; LOCH, 2014). Isso ocorre com base na geração de flexibilidade organizacional para adaptação às mudanças ambientais e, consequentemente, para a obtenção de melhor desempenho nas organizações, sob uma visão de formação da estratégia como um processo de aprendizagem experiencial coletivo, com possibilidades de insights sobre como e por que as organizações precisam mudar (BALBASTRE-BENAVENT; CANET-GINER, 2011; KHANAGHA; VOLBERDA; OSHRI, 2014). A seguir, trata-se da estratégia no âmbito das universidades.

\section{Estratégia e universidades}

A investigação sobre a teoria da estratégia (ELBANNA, 2006; MINTZBERG; WATERS, 1985; PETTIGREW, 1992) e sobre o âmbito universitário encontra-se em expansão desde as últimas décadas. Nessa trajetória, há duas posições sobre o assunto (MASSEN; POTMAN, 1990; WALKER, 2013).

A primeira tece críticas quanto à aplicabilidade de conceitos, abordagens e ferramentas estratégicas às universidades, dada a complexidade que caracteriza esse tipo de instituição (MEYER JÚNIOR; LOPES, 2015), já que a racionalidade voltada à lógica de mercado, bem como os usos práticos da gestão estratégica, iria de encontro a essa complexidade e poderia desconsiderar aspectos específicos que norteiam a gestão de ensino, por conter pressupostos de valor intrínsecos, os quais entrariam em conflito com o mundo acadêmico (EASTERBY-SMITH, 1987; LINDSAY, 1981; MEYER JÚNIOR; LOPES, 2015).

A segunda posição não constata uma dicotomia inconciliável entre os dois construtos, e procura, então, analisar os aspectos dialógicos entre a estratégia e as universidades, em que a adoção de modelos de outros tipos de organização pode colaborar para tornar explícitas as decisões sobre o ensino superior (EASTERBY-SMITH, 1987; RIZZATTI; RIZZATTI JUNIOR, 2004).

Ademais, entende-se que os temas estratégia e universidade, quando trabalhados em conjunto, focalizam atenção nos padrões decisórios que se formam no curso de mudanças, sob o enfoque da compreensão do papel dos atores envolvidos e sob a égide do aprendizado e da melhoria na gestão universitária como um todo, paralelamente à retenção de valores originais desse tipo de instituição (COHEN; MARCH; OLSEN, 1972; EASTERBY-SMITH, 1987; JARZABKOWSKI, 2005; JOHNSON; SCHOLES; WHITTINGTON, 2005; RIZZATTI; RIZZATTI JUNIOR, 2004; WALKER, 2013).

No que se refere ao aprofundamento de teorias voltadas à estratégia e sua repercussão na gestão universitária, Jarzabkowski (2005) argumenta que, com 
determinadas exceções, as universidades não são vistas como contextos de pesquisa estratégica, dado que predomina o foco de investigação no setor privado e suas noções de livre concorrência no mercado. No entanto, as universidades realmente fazem estratégia e se caracterizam como contextos ideais para se demonstrar a profundidade e a importância de se estudar o tema nesse tipo de instituição (JARZABKOWSKI, 2005). A seguir, trata-se do Sistema de Avaliação da Pós-Graduação nacional.

\section{O SISTEMA DE AVALIAÇÃO DA PÓS-GRADUAÇÃO BRASILEIRA}

O Sistema de Avaliação da Pós-graduação brasileira tem ampliado sua credibilidade ao longo dos anos, em âmbito nacional e internacional (MARTINS; MACCARI, 2015; OLIVEIRA; ALMEIDA, 2011). Para tanto, a Capes realiza investimentos no aprimoramento desse sistema, que é composto por dois processos: "Entrada", o qual se relaciona à Análise de Propostas de Cursos Novos (APCN), e "Permanência", que trata da Avaliação Periódica dos Cursos de Pós-Graduação, os quais já se encontram em funcionamento e fazem parte do Sistema Nacional de Pós-Graduação (SNPG) e são submetidos ao Sistema de Avaliação da Pós-Graduação coordenado pela Capes. Ambos os processos norteiam-se pelos seguintes fundamentos: a) reconhecimento e confiabilidade, fundados na qualidade assegurada pela análise dos pares; b) critérios debatidos e atualizados pela comunidade acadêmico-científica a cada período avaliativo; c) transparência, com ampla divulgação das decisões, ações e resultados (BRASIL, 2008).

Diante do exposto, compreende-se o impacto que o Sistema de Avaliação da Pós-Graduação tem na consolidação da pós-graduação nacional. Isso se materializa à medida que o sistema procede tanto à avaliação quanto à certificação dos programas avaliados, o que ocorre de duas maneiras: por meio de um acompanhamento anual, voltado a orientar e apontar questões que podem ser melhoradas, bem como por uma Avaliação Quadrienal, direcionada a aferir o desempenho dos programas, com base nos dados que são inseridos por eles, para as duas situações, na Plataforma Sucupira (BRASIL, 2008; MARENCO, 2015; MARTINS; MACCARI, 2015; TEIXEIRA; MACCARI; MARTINS, 2016).

Ressalta-se que somente por meio do Sistema de Avaliação é que o Conselho Nacional de Educação do Ministério da Educação (MEC) autoriza o funcionamento e atesta a validade nacional dos diplomas de mestrado (acadêmico e profissional) e de doutorado dos programas de pós-graduação (BRASIL, 2016c). Os programas recebem uma pontuação de desempenho na avaliação em uma escala que vai de 1 a 7, sendo 3 a pontuação mínima para que programas façam parte do SNPG (MACCARI et al., 2009). 
Ademais, aos programas que não alcançam essa nota, é vedada a abertura de novas turmas até que seja realizada nova avaliação; já as pontuações 6 e 7 indicam desempenho equivalente ao padrão internacional de instituições em termos de qualidade (FAGÁ; QUONIAM, 2015; MARTINS et al., 2012). Além disso, a avaliação é externa (tanto à Capes quanto aos programas avaliados), conduzida por comissões vinculadas às 49 áreas de avaliação, dentre as quais os membros atuam como avaliadores ad hoc, selecionados por meio de critérios que levam em conta o reconhecimento da comunidade científica, experiência de atuação na pós-graduação, área e instituição de vínculo e a região do país (MACCARI et al., 2009).

Destaca-se, ainda, que a publicização dos dados referentes às avaliações, realizada pela Capes, oportuniza que as instituições avaliadas tenham acesso ao desempenho e às características das demais, de modo que isso lhes possibilita conhecer e absorver o que pode ser usado para potencializar seu próprio desempenho. Tal fato pode ser vinculado ao conceito de isomorfismo, no que se refere ao contexto do Sistema de Avaliação da Pós-Graduação nacional, diante das pressões pelo atendimento de seus indicadores. Percebe-se que as instituições avaliadas têm adotado práticas isomórficas, tanto coercitivas quanto miméticas e normativas, com base no que se apresenta em seu ambiente de atuação (MACCARI; MARTINS; ALMEIDA, 2015; MACHADO-DA-SILVA, 2003).

Além disso, outro aspecto relacionado à divulgação de informações acerca do Sistema de Avaliação da Pós-Graduação é a prestação de contas, ou seja, a forma pela qual os recursos são distribuídos e aplicados, o que é de interesse da sociedade como um todo (FAGÁ; QUONIAM, 2015; SHIGAKI; PATRUS, 2012; VERHINE; DANTAS, 2009). O resultado da avaliação auxilia, ainda, na identificação de fragilidades, assimetrias regionais e de áreas do conhecimento para o processo de ações de melhoria, bem como norteia políticas de levantamento e distribuição de recursos aos programas, de modo a operacionalizar o fomento à ampliação e à consolidação da qualidade e da excelência da pós-graduação nacional (BRASIL, 2008; MACCARI; NISHIMURA, 2014; MORITZ; MORITZ; MELO, 2011).

Nessa direção, os eixos temáticos a serem atendidos na avaliação e que abrangem todas as áreas de conhecimento são: I - Proposta do Programa; II - Corpo Docente; III - Corpo Discente; IV - Produção Intelectual; e V - Inserção Social (MARCHELLI, 2007). Destaca-se que tais indicadores fazem parte de uma Ficha de Avaliação, que é disponibilizada às Comissões de Área, de modo a padronizar e uniformizar o processo de análise (MARTINS; MACCARI, 2015).

Outro documento que visa a contribuir para o processo de avaliação é o Documento de Área, que apresenta as características da Área de Avaliação, informa sobre seu estágio atual, traz considerações sobre a avaliação quadrienal do período, disponibiliza as fichas de avaliação nas quais os indicadores são avaliados, 
de acordo com o tipo de curso stricto sensu, bem como explica os critérios da área para a atribuição dos conceitos de nível internacional (6 e 7) e abarca aspectos relativos à produção técnica e tecnológica, as quais também são avaliadas, para, então, serem sintetizadas no Relatório de Avaliação, que traz o diagnóstico do desempenho dos cursos avaliados (MACCARI et al., 2015).

Diante do exposto e com base nos propósitos deste estudo, optou-se por apresentar os indicadores citados a partir da Área de Avaliação: Administração Pública e de Empresas, Ciências Contábeis e Turismo, que faz parte da Grande Área do Conhecimento Ciências Sociais Aplicadas (BRASIL, 2016a). Nesse sentido, em termos de contextualização dessa Área de Avaliação, no ano de 2016 ela era composta por 184 programas, com um total de 11 em Administração Pública, 135 em Administração de Empresas, 27 em Ciências Contábeis e 11 em Turismo (BRASIL, 2016a).

Destaca-se que a comissão de área designada para realizar a avaliação tem por dever se manifestar acerca de cada item contemplado nos indicadores, no sentido de orientar, propor recomendações e até mesmo fazer as devidas advertências, se for o caso (MARTINS; MACCARI, 2015). Nessa direção, para auxiliar o trabalho de tais comissões, fichas aparecem descritas nos Documentos de Área, os quais trazem informações detalhadas sobre o que é avaliado em cada indicador, de modo que haja padronização e isonomia na análise tanto dos aspectos qualitativos quanto dos quantitativos da avaliação. Além disso, para indicadores da avaliação que abrangem a produção científica dos programas, é utilizado também o Sistema Qualis, de avaliação de periódicos, no qual estes são pontuados por área de conhecimento (BRASIL, 2017b).

É necessário, ainda, como contraponto, mencionar que, diante dos aspectos citados da avaliação, devido à forma e à estrutura do Sistema de Avaliação, bem como pelo modo como se processa a certificação dos programas avaliados, críticas têm sido apontadas de que tanto o sistema quanto a avaliação valorizam demasiadamente o produtivismo, a quantificação e a homogeneização entre os programas avaliados, sem considerar as particularidades de cada instituição, bem como as singularidades das regiões do país em que se encontram (FAGÁ; QUONIAM, 2015; MARENCO, 2015; OLIVEIRA; ALMEIDA, 2011).

Nesse cenário, entende-se que o Sistema de Avaliação da Pós-Graduação possui aspectos a serem melhorados, e as críticas a ele servem para colaborar com seu processo de aperfeiçoamento e evolução. Isso faz com que o sistema se consolide ainda mais como uma ferramenta que auxilia no processo de autoconhecimento das instituições avaliadas, de maneira que elas procurem discutir e sanar suas deficiências junto à Capes, potencializar suas qualidades e, assim, propiciar cada vez mais o desenvolvimento econômico, científico e tecnológico do país, à medida que planejam e executam suas ações em prol disso (GOUVÊA, 2012; MACCARI et al., 
2014; MACHADO-DA-SILVA, 2003; MARTINS; MACCARI, 2015; MORITZ; MORITZ; MELO, 2011). Com o exposto, tem-se como proposição teórica de estudo que o Sistema de Avaliação da Pós-Graduação Brasileira influencia as estratégias dos programas avaliados. Na sequência, passa-se aos métodos adotados.

\section{PROCEDIMENTOS METODOLÓGICOS}

Esta pesquisa teórico-empírica adotou a abordagem qualitativa, a partir da identificação de estratégias para atender ao Sistema de Avaliação da Pós-Graduação brasileira, no ambiente do PPGA/UFSC, local onde os fatos investigados ocorreram, ou seja, em seu ambiente natural (BABBIE, 1998; MARCONI; LAKATOS, 2010). Neste estudo, as investigações foram contempladas sob a perspectiva de elucidação da problemática no contexto social e organizacional do PPGA.

Este estudo se caracteriza como descritivo, dado que foi realizado o relato pormenorizado do objeto de estudo, em termos de descrição das características do PPGA e das estratégias vigentes neste e dos desafios estratégicos enfrentados pelo programa (BABBIE, 1998; VERGARA, 2007), e, ainda, como ex-post-facto (MARCONI; LAKATOS, 2010), porque contemplou o recorte temporal do quadriênio 2013-2016 da avaliação aplicada pelo Sistema de Avaliação da Pós-Graduação, que se constitui como o último quadriênio com resultados publicados pela Capes. Os dados referentes a esse período avaliativo foram coletados em setembro do ano de 2017. Em termos de contribuição prática do estudo, por sua natureza aplicada (VERGARA, 2007), foram apontadas possibilidades de melhorias no ambiente pesquisado a partir das fragilidades presentes na gestão estratégica do PPGA em relação aos indicadores da avaliação da Capes.

A estratégia de pesquisa contemplou um estudo de campo, em alinhamento com a abordagem qualitativa e com foco na realidade local e suas particularidades e conexões com o ambiente de sua inserção. Houve, ainda, o suporte das pesquisas bibliográfica e documental (ROESCH, 2009; VERGARA, 2007). A seleção da unidade de estudo, o PPGA/UFSC, deu-se de modo intencional. Ou seja, em que o interesse do pesquisador se volta para opinião, ações ou intenções relativas a determinados atores e abrange elementos de uma realidade específica, sem interesse em generalizações, mas sim no aprendizado que pode ser alcançado no percurso da investigação (MARCONI; LAKATOS, 2015). Em relação à caracterização dos sujeitos do estudo, optou-se por abranger atores que integraram o contexto da gestão do PPGA e, desse modo, envolveram-se no processo estratégico do programa.

A partir do quadriênio que delimita o recorte temporal do estudo, contemplaram-se dois coordenadores e um subcoordenador do PPGA, já que um 
dos subcoordenadores atuou no mesmo período também como coordenador. Ressalta-se que os entrevistados receberam informações acerca dos propósitos deste estudo, bem como sobre o uso restrito de suas contribuições para os fins de investigação científica, concordando em assinar um Termo de Consentimento Livre e Esclarecido (TCLE).

A pesquisa bibliográfica foi utilizada para subsidiar a construção do arcabouço de fundamentação teórica. O recorte temporal de literatura proposto foi entre os anos de 1996 a 2017. O primeiro, 1996, foi selecionado por conta de ser o marco da criação da Lei de Diretrizes e Bases da Educação (LDB) (BRASIL, 1996), que possibilitou significativas mudanças no sistema educacional brasileiro e contempla diretrizes voltadas à pós-graduação. Para o período final, 2017, pretendeu-se localizar obras atuais sobre os assuntos elencados.

O suporte da pesquisa documental que colabora, ainda, para a elucidação de questões de pesquisa relativas a estudos ex-post-facto (SAUNDERS; LEWIS; THORNHILL, 2009), foi utilizado para se conhecer a estrutura do PPGA, ou seja, de que forma o programa atua por meio de normativas e editais publicados em seu site, além de documentos como atas e seu regimento interno. Sobre a avaliação, consultou-se o Documento de Área para conhecer os parâmetros da área de Administração Pública e de Empresas, Ciências Contábeis e Turismo, na qual o PPGA se insere. Ademais, foram consultados relatórios de indicadores desses períodos para levantar informações sobre a trajetória do programa na avaliação, além, é claro, do relatório do quadriênio 2013-2016.

A coleta de dados foi realizada em duas etapas, sendo a primeira constituída de entrevista, por meio da aplicação do pré-teste do instrumento roteiro semiestruturado, o qual contou com as dimensões baseadas nos indicadores do Sistema de Avaliação da Capes: a) Proposta do Programa; b) Corpo Docente; c) Corpo Discente, teses e dissertações; d) Produção Intelectual; e) Inserção Social. A segunda etapa, após a realização dos ajustes necessários, seguiu para a aplicação do instrumento aos sujeitos da pesquisa, bem como para a coleta de dados secundários. Sobre a execução das entrevistas, o tempo médio de duração foi de 40 minutos.

Foi utilizada análise de conteúdo dos dados primários por categorização analítica (BARDIN, 2011). As estratégias do PPGA foram identificadas e categorizadas por meio dos critérios de exclusão mútua e de pertinência teórica (BARDIN, 2011). Então, a partir da tipologia descrita pelos teóricos Mintzberg e Waters (1985), foi estabelecida uma categoria analítica que se caracteriza por estratégias que assumem a natureza deliberada ou emergente, conforme o Quadro 2. Já em relação aos dados secundários, ou seja, documentos, tanto o tratamento quanto a apresentação ocorreram por análise documental. Nela, foram analisados os padrões de informações que eram aderentes aos propósitos do estudo e que poderiam corresponder 
aos tipos de estratégias descritos na literatura (VERGARA, 2007), de modo a identificar nos tipos documentais dados que fossem relevantes para a investigação e que também dialogassem com a categoria analítica estabelecida.

QUADRO 2 - Escopo analítico do estudo

\begin{tabular}{|c|c|c|c|c|}
\hline OBJETIVO & $\begin{array}{c}\text { TEORIAS } \\
\text { ESTRUTURANTES }\end{array}$ & TEÓ & $\begin{array}{c}\text { CATEGORIA } \\
\text { ANALÍTICA (CA) }\end{array}$ & $\begin{array}{l}\text { DIMENSÕES TEÓRICAS DO } \\
\text { TRABALHO ESTRATÉGICO }\end{array}$ \\
\hline $\begin{array}{l}\text { Identificar } \\
\text { estratégias } \\
\text { relacionadas a } \\
\text { atender ao Sistema } \\
\text { de Avaliação da } \\
\text { Pós-Graduação em } \\
\text { um programa de } \\
\text { pós-graduação em } \\
\text { Administração de } \\
\text { uma universidade } \\
\text { federal }\end{array}$ & $\begin{array}{c}\text { ESTRATÉGIA: } \\
\text { Definição: } \\
\text { Relaciona-se às } \\
\text { organizações e seu } \\
\text { entorno. } \\
\text { Contempla ações } \\
\text { deliberadas e } \\
\text { emergentes nos } \\
\text { processos de formação } \\
\text { e implementação de } \\
\text { estratégias. }\end{array}$ & $\begin{array}{c}\text { P1: O Sistema } \\
\text { de Avaliação da } \\
\text { Pós-Graduação } \\
\text { brasileira } \\
\text { influencia as } \\
\text { estratégias } \\
\text { dos programas } \\
\text { avaliados. }\end{array}$ & $\begin{array}{c}\text { A estratégia } \\
\text { (seja deliberada } \\
\text { ou emergente) } \\
\text { em relação } \\
\text { ao tipo de } \\
\text { indicador a ser } \\
\text { atendido na } \\
\text { avaliação da } \\
\text { Capes. }\end{array}$ & $\begin{array}{l}\text { Estão presentes nos } \\
\text { fluxos das ações } \\
\text { organizacionais: } \\
\text { a) atuação dos agentes } \\
\text { sociais; } \\
\text { b) explicitação de ações; } \\
\text { c) controle de ações; } \\
\text { d) gestão de consenso; } \\
\text { e) aprendizado; } \\
\text { f) orientação para } \\
\text { mudanças futuras. }\end{array}$ \\
\hline
\end{tabular}

Fonte: Elaboração das autoras (2017).

Conforme apresentado no Quadro 2, procurou-se alinhar o objetivo geral às teorias estruturantes e, a partir disso, estabelecer a proposição teórica por meio da qual foi possível a criação da categoria analítica central para a elaboração dos eixos do roteiro de entrevista. Na análise, buscou-se identificar, em alinhamento com a categoria analítica, como as dimensões do trabalho estratégico se apresentaram nas estratégias vigentes no PPGA.

\section{APRESENTAÇÃO DE DADOS E DISCUSSÃO DE RESULTADOS}

\section{O Programa de Pós-Graduação em Administração da UFSC}

O PPGA é vinculado ao Departamento de Ciências da Administração (CAD) e ao Centro de Ensino Socioeconômico da UFSC. O PPGA iniciou suas atividades no ano de 1978, com o curso de mestrado. Posteriormente, em 2008, foi criado o curso de doutorado, ambos reconhecidos pela Capes, em pleno funcionamento e classificados com a nota 4, até o ano de 2016, no Sistema de Avaliação da Pós-Graduação (BRASIL, 2016c, 2017a).

A estrutura de gestão do PPGA é composta por uma coordenação didática e uma administrativa. A primeira fica a cargo do colegiado do programa, que assume as funções de colegiado pleno. Quanto à composição de membros, fazem parte o coordenador, como presidente, o subcoordenador, como vice-presidente, todos os professores permanentes credenciados ao programa, o chefe do Departamento de Ciências da Administração, bem como representantes discente, eleitos por seus pares na proporção de um para cada cinco docentes atuantes no colegiado (UFSC, 2011). A segunda coordenação fica sob a responsabilidade do coordenador e do 
subcoordenador, os quais são eleitos pelos membros do colegiado para um mandato de dois anos, com possibilidade de uma única recondução. Ademais, a coordenação é assessorada por uma secretaria (UFSC, 2011; BRASIL, 2007).

Por fim, o programa possui uma estrutura curricular baseada na Área de Concentração intitulada Organizações e Sociedade e Desenvolvimento, que contempla cinco linhas de pesquisa, a saber: a) Finanças e Desenvolvimento Econômico; b) Produção e Desenvolvimento; c) Organizações e Sociedade; d) Marketing e Estratégia nas Organizações; e) Gestão Universitária (BRASIL, 2016c). As ações inerentes aos propósitos dessas linhas de pesquisa são realizadas por docentes e discentes, tanto por meio das disciplinas ofertadas, como por sua atuação nos 19 grupos de pesquisa criados ao longo da trajetória do PPGA (BRASIL, 2016c; UFSC, 2017). A seguir, trata-se das estratégias do PPGA.

\section{As estratégias do PPGA no quadriênio 2013-2016}

Conforme apresentado na seção de métodos adotados, procedeu-se a busca de dados em documentos e se investigou a posição dos entrevistados, identificados como E1, E2 e E3, acerca das estratégias do PPGA relacionadas aos cinco indicadores do Sistema de Avaliação da Pós-Graduação no quadriênio 2013-2016. Inicia-se a discussão dos resultados pelo indicador Proposta do Programa, conforme o disposto no Quadro 3.

QUADRO 3 - Estratégias voltadas ao indicador Proposta do Programa

\begin{tabular}{|c|c|c|}
\hline $\begin{array}{c}\text { INDICADOR DO SISTEMA } \\
\text { DE AVALIAÇÃO CAPES }\end{array}$ & ESTRATÉGIA & $\begin{array}{c}\text { AÇÕES ESTRATÉGICAS DE } \\
\text { FORMAÇÃO E IMPLEMENTAÇÃo }\end{array}$ \\
\hline \multirow{3}{*}{\begin{tabular}{c} 
Proposta do Programa \\
\cline { 2 - 3 }
\end{tabular}} & $\begin{array}{c}\text { Ampliação de linhas de pesquisa } \\
\text { (emergente) }\end{array}$ & $\begin{array}{c}\text { - criação de duas linhas: Marketing e } \\
\text { Estratégia e Gestão Universitária. }\end{array}$ \\
\cline { 2 - 3 } & $\begin{array}{c}\text { Internacionalização do programa } \\
\text { (deliberada) }\end{array}$ & $\begin{array}{c}\text { - adequação do processo de seleção de } \\
\text { discentes. } \\
\text { - incentivo ao pós-doutorado docente. }\end{array}$ \\
\cline { 2 - 3 } & $\begin{array}{c}\text { Adequação do perfil docente } \\
\text { (deliberada) }\end{array}$ & $\begin{array}{c}\text { - criação de comissões e alteração de } \\
\text { procedimentos de credenciamento. }\end{array}$ \\
\hline
\end{tabular}

Fonte: Dados da pesquisa (2017).

Consideradas as três estratégias identificadas para o indicador Proposta do Programa (Quadro 3), destaca-se que a primeira, de acordo com os entrevistados, se deu sem qualquer direcionamento da gestão do programa, o que a caracterizou como de natureza emergente. Essa estratégia ocorreu no ano de 2015, e seu processo de formação se desenvolveu no ambiente interno do programa, por meio de determinados docentes que apontaram a necessidade de ampliação de linhas de pesquisa. Ou seja, a "mola propulsora" dessa estratégia foi a iniciativa de docentes, como agentes sociais do processo estratégico integrantes do PPGA, que durante suas atividades e estudos entenderam a necessidade de criação de duas 
novas linhas de pesquisa, as quais se materializaram como ação estratégica de criação das linhas de Marketing e Estratégia e Gestão Universitária.

Além disso, ao se fazer o cruzamento das informações dos entrevistados com a base documental, verificou-se que, embora os entrevistados citassem a influência interna nessa estratégia, no relatório de avaliação do ano de 2015 disponível na Plataforma Sucupira, a gestão do programa também identificou uma crescente demanda externa por pesquisas nas áreas de Marketing e Planejamento Estratégico (BRASIL, 2015). Ou seja, essa conciliação de dados sugere, de acordo com o apontado na literatura utilizada neste estudo, que tal estratégia não seria puramente emergente.

Diante do exposto, identificou-se que o programa buscou atender demandas advindas tanto de seu ambiente interno como externo. Para a implementação dessa estratégia, verificou-se nas atas consultadas a operacionalização dos trâmites burocráticos referentes às novas linhas e a alocação de docentes para atuar nelas. Tal processo respeitou a dimensão teórica da gestão do consenso, dado que os membros do colegiado do programa aprovaram sua implementação.

No que se refere à segunda estratégia identificada, de internacionalização do programa, esta se caracterizou como do tipo deliberada, dado que partiu da gestão do PPGA, e, pela fala dos entrevistados, tal gestão considerou as regras do Sistema de Avaliação da Capes para definir como tal estratégia a que deveria ser colocada em prática. Ou seja, devido à pressão coercitiva do ambiente externo, que se materializou pelas diretrizes de avaliação da pós-graduação, a gestão superior definiu a maneira de responder ao desafio apresentado. Conforme o Quadro 3, foram duas as ações estratégicas norteadoras do trabalho de gestão estratégica em curso.

A primeira ação foi a revisão das normas que regiam o processo seletivo de discentes, para adequá-lo ao perfil de internacionalização de programas apontado pela Capes. Nesse sentido, E3 comentou que não havia problemas em relação à prospeç̧ão de alunos. Então, foi trabalhado o ajuste do edital quanto à clareza das regras. E1 informou, ainda, ações relacionadas à seleção de estudantes e mencionou aspectos da implementação da estratégia, especificamente, durante as entrevistas do processo seletivo, para identificar os candidatos que possuíssem interesse em fazer o doutorado sanduíche (no exterior). Ou seja, mais uma vez o papel dos agentes sociais docentes ressalta no processo estratégico, mas dessa vez como responsáveis pela implementação estratégica.

A segunda ação estratégica era inerente ao incentivo para que professores do PPGA fizessem pós-doutoramento, pois, segundo E1, havia uma endogenia em relação à formação de docentes em um mesmo programa de pós-graduação. Nesse sentido, o elemento que emerge é a gestão do consenso, porque o processo de 
afastamento parte da iniciativa docente em buscar o nível de pós-doutoramento, em colaboração com os objetivos de atendimento da estratégia estabelecida pela gestão do PPGA no contexto da avaliação da pós-graduação.

Pelo citado anteriormente, verificou-se que a implementação da estratégia deliberada de internacionalização do PPGA contou, ainda, com elementos relacionados ao nível de explicitação e de controle de gestão estratégica, dado que as ações adotadas para sua implementação foram devidamente materializadas em normativas e no trabalho de parametrização voltado ao acompanhamento das ações em curso, mediante o que preconiza o Sistema de Avaliação da Capes.

Acerca da terceira estratégia, voltada ao perfil docente, verificou-se que se tratava de uma estratégia deliberada. Na visão de E1, o processo de implementação dessa estratégia demorou devido à posição do programa em aguardar a edição de novas normas referentes à sistemática de avaliação. Em sua fala pode-se notar que a estratégia foi diretamente afetada pela decisão da gestão do programa, na qual os gestores fizeram a leitura do ambiente externo considerando a avaliação da Capes, a qual se constituiu como fator-chave para o adiantamento da implementação estratégica.

De acordo com E2, após a edição das normas da Capes, a implementação dessa estratégia seguiu por meio da ação estratégica de criação de duas comissões de trabalho, cujos objetivos estavam relacionados "a analisar e reescrever, atualizando critérios de credenciamento e descredenciamento de docentes, isso bem alinhado com o que a Capes coloca”. As afirmações de E1, E2 e E3 também aparecem registradas nas fontes documentais, como atas que aprovaram a nominata dos membros das comissões citadas. Outra fonte foi a Resolução n. 1 de 2015 do programa (UFSC, 2015), que materializou as regras de credenciamento e descredenciamento docente.

Nessa conjuntura, as dimensões teóricas que se alinharam ao processo estratégico de conteúdo relacionado à estratégia em questão foram as de atuação de agentes-chave e de explicitação de ações. Na primeira, os agentes da estratégia compunham as comissões estabelecidas pela gestão do PPGA, assim convergindo para a segunda dimensão, desenvolvendo critérios relacionados ao perfil desejado de docentes no contexto da avaliação da Capes. Com a apresentação do Quadro 4, passa-se à análise do segundo indicador da avaliação da Capes.

QUADRO 4 - Estratégias voltadas ao indicador Corpo Docente

\begin{tabular}{|c|c|c|}
\hline INDICADOR & ESTRATÉGIA & $\begin{array}{c}\text { AÇÕES ESTRATÉGICAS DE } \\
\text { FORMAÇÃO E IMPLEMENTAÇÃO }\end{array}$ \\
\hline Corpo Docente & não consta & não constam \\
\hline
\end{tabular}

Fonte: Dados da pesquisa (2017). 
Pelo exposto no Quadro 4, inicia-se a descrição do indicador Corpo Docente com base nos aspectos relacionados à formação, dedicação e adequação do corpo docente, em alinhamento aos propósitos de pesquisa e também ao que preconiza o indicador Proposta do Programa ao qual se relaciona diretamente.

Os entrevistados relataram não existir uma estratégia ou ações estratégicas específicas para esse indicador. Por outro lado, E1 reforçou a preocupação com a necessidade de combate à endogenia na formação dos docentes do Programa. E3 comentou, também, sobre as discussões no âmbito da coordenação inerentes à compatibilidade do corpo docente em relação às linhas de pesquisa vigentes, quanto à produção científica e orientação de estudantes.

Quanto à distribuição de atividades de pesquisa e formação, bem como sobre a contribuição do corpo docente com o desenvolvimento do ensino e da pesquisa na graduação, os entrevistados foram unânimes em dizer que, no caso da UFSC, dada a obrigatoriedade de os docentes lecionarem na graduação, tal contribuição em nível de ensino não era problemática.

Diante do cenário apresentado, verificou-se na fala dos entrevistados que, embora não existissem estratégias planejadas ou tidas como emergentes no contexto de gestão estratégica do programa para o indicador Corpo Docente, havia a preocupação não formalizada em atendê-lo, e isso foi considerado como estratégico pelos entrevistados, em termos de orientação e incentivo aos envolvidos e ao repasse de informações. A seguir, no Quadro 5, passa-se ao indicador Corpo Discente.

QUADRO 5 - Estratégias voltadas ao indicador Corpo Discente

\begin{tabular}{|c|c|c|}
\hline \multirow{2}{*}{ INDICADOR } & ESTRATÉGIA & $\begin{array}{c}\text { AÇÕES ESTRATÉGICAS DE } \\
\text { FORMAÇÃO E IMPLEMENTAÇÃo }\end{array}$ \\
\hline \multirow{2}{*}{ Corpo Discente } & $\begin{array}{c}\text { Identificar fragilidades na avaliação do } \\
\text { programa (emergente) }\end{array}$ & $\begin{array}{c}\text { - adequação de parâmetros de } \\
\text { informações com base nos resultados das } \\
\text { avaliações anteriores. }\end{array}$ \\
\cline { 2 - 3 } & $\begin{array}{c}\text { Formação de discentes bolsistas } \\
\text { (deliberada) }\end{array}$ & $\begin{array}{c}\text { - não foram identificadas ações para além } \\
\text { de acompanhamento por amostragem. }\end{array}$ \\
\hline
\end{tabular}

Fonte: Dados da pesquisa (2017).

Cabe esclarecer que o indicador Corpo Discente engloba teses e dissertações como elemento básico. Identificou-se pela fala dos entrevistados a presença de estratégias de natureza emergente e deliberada. Nesse sentido, pode-se considerar, com base nos dados da pesquisa, que culminou como uma estratégia emergente a identificação de fragilidades do programa na avaliação, considerado o fluxo de informações que abarcavam os prazos de defesa dos discentes, o número máximo de orientandos por docente e a coerência entre os trabalhos desenvolvidos e os projetos de pesquisa dos professores, os quais compunham itens de interesse no processo avaliativo da Capes. 
Diante disso, a ação que se configurou no âmbito da gestão estratégica do PPGA foi a de adequação de parâmetros voltados aos tipos de informações anteriormente citados, com base nos resultados anteriores alcançados pelo PPGA no Sistema de Avaliação da Capes. Assim, emergiu, ainda, como dimensão inerente ao fluxo de ações dessa estratégia, a gestão do consenso entre docentes em relação aos parâmetros que importavam para o indicador em questão, como, por exemplo, não ultrapassar o número máximo de orientandos, bem como as dimensões de aprendizado e de mudanças futuras, com base nos resultados que a implementação dessa estratégia poderia alcançar junto ao Sistema de Avaliação da Capes.

Nessa direção, e para finalizar o indicador, os entrevistados foram questionados acerca da eficiência do programa em relação à formação de discentes bolsistas. Pelas falas, verificou-se que havia uma estratégia deliberada voltada à formação de desses discentes, porém não se pode aferir como tal estratégia teria sido efetivamente implementada em termos de mensuração de resultados. Somente foi relatado o acompanhamento discente por amostragem, o que poderia comprometer a efetividade da implementação de tal estratégia de acordo com o que preconiza a dimensão teórica da explicitação de ações.

Além disso, na base documental também não foram encontrados registros relacionados a uma possível implementação dessa estratégia. Assim, a dimensão teórica do trabalho que pode ser identificada foi a atuação de agentes sociais, mas esta se limitou ao quadro gestor do programa, que concebeu a estratégia citada pelos entrevistados. Em seguida, passa-se ao indicador Produção Intelectual, no Quadro 6.

QUADRO 6 - Estratégias voltadas ao indicador Produção Intelectual

\begin{tabular}{|c|c|c|}
\hline INDICADOR & ESTRATÉGIA & $\begin{array}{c}\text { AÇÕES ESTRATÉGICAS DE } \\
\text { FORMAÇÃO E IMPLEMENTAÇÃO }\end{array}$ \\
\hline $\begin{array}{c}\text { Produção } \\
\text { Intelectual }\end{array}$ & $\begin{array}{c}\text { Diagnosticar a produção intelectual } \\
\text { (deliberada) }\end{array}$ & - rotinas de acompanhamento \\
\hline
\end{tabular}

Fonte: Dados da pesquisa (2017)

Conforme o Quadro 6, para o indicador Produção Intelectual, que contempla a ampliação de produções qualificadas e sua distribuição entre corpo docente e discente, identificou-se, pelas falas dos pesquisados, que havia uma estratégia deliberada para esse indicador. O processo estratégico de formação dessa estratégia seguiu estritamente a necessidade de atendimento ao Sistema de Avaliação da Capes em termos de fluxos de ações organizacionais (E1). Para tanto, a implementação estratégica ocorreu por meio de ações que se materializaram como rotinas de acompanhamento.

A dimensão teórica do trabalho estratégico que emergiu foi a de controle de ações, as quais eram descritas em relatórios de gestão. E1 complementou o exposto 
ao citar que informações também eram coletadas na Plataforma Sucupira, bem como que os resultados das análises realizadas eram discutidos em reuniões do colegiado, o que também consta das atas deste, sem a menção a desempenhos individuais: "no Sucupira a gente procura medir a qualidade, aí chega na reunião de colegiado e diz: olha, a nossa média está assim, nós precisamos melhorar, mas não diz professor A, B ou C". Nesse sentido, constatou-se que E2 trouxe complementações ao exposto por E1, ao comentar que: "Então, o que a gente fazia é avaliar a produção de docentes, tanto do ponto de vista quantitativo como qualitativo".

Ao se considerar as evidências relacionadas ao indicador Produção Intelectual, presentes nas atas e nas entrevistas, compreende-se que o programa buscou implementar sua estratégia de diagnóstico utilizando-se de rotinas estratégicas inerentes à busca e seleção de informações e um trabalho compartilhado com os atores envolvidos no alcance desse indicador, o que ressaltou também a presença da atuação conjunta dos agentes sociais docentes e gestores.

Além disso, a implementação estratégica contou com o uso de recursos tecnológicos, de capital humano e materiais para auxiliar esse processo. Identificou-se, também, a preocupação em aperfeiçoar a estratégia até então vigente, alinhando-se aspectos de conteúdo e de processo estratégico, por meio de alteração no procedimento inerente ao controle de produção docente e de maneira a proceder ajustes necessários que pudessem melhorar o desempenho do programa nesse indicador, contemplando a dimensão de orientação interna para mudanças futuras. Na sequência, no Quadro 7, analisa-se o indicador Inserção Social.

QUADRO 7 - Estratégias voltadas ao indicador Inserção Social

\begin{tabular}{|c|c|c|}
\hline INDICADOR & ESTRATÉGIA & $\begin{array}{c}\text { AÇÕES ESTRATÉGICAS DE } \\
\text { FORMAÇÃO E IMPLEMENTAÇÃo }\end{array}$ \\
\hline Inserção Social & não consta & não constam \\
\hline
\end{tabular}

Fonte: Dados da pesquisa (2017).

Conforme ilustrado no Quadro 7, o último eixo das entrevistas abordou o indicador Inserção Social. Nesse sentido, os entrevistados foram arguidos acerca da inserção regional ou nacional do programa, bem como sobre a política para egressos, a integração com outros programas e centros de pesquisa e a visibilidade em termos de atuação do PPGA. Verificou-se, pela fala dos entrevistados, que não havia uma estratégia no âmbito da gestão do programa para atender a esse indicador, nem mesmo de natureza emergente. Nesse contexto, as ações destinadas à inserção regional ou nacional, bem como as relativas à integração com outros programas e órgãos ligados à pesquisa, ficavam a cargo de iniciativas dos docentes, que buscavam parcerias e promoviam eventos e demais ações ligadas a esses dois itens. 
Em complementação, identificou-se na base documental de relatórios de dados enviados à Plataforma Sucupira, referentes ao quadriênio 2013-2016, que o programa expôs atividades e convênios realizados pelos docentes em prol do atendimento a esse indicador, de maneira a demonstrar o que foi colocado em prática. Embora, na percepção dos entrevistados, não houvesse estratégias formalizadas ou que possam ter sido formadas de maneira emergente para atender ao indicador em análise, consta do relatório de dados enviados pelo programa, referente ao ano de 2016 (BRASIL, 2016b), a ciência do PPGA quanto à relevância do acompanhamento de egressos. Consta, também, que o programa se utilizou de dados quantitativos disponíveis no site criado pela UFSC para esse fim, bem como de buscas no Currículo Lattes dos docentes e estudantes para apresentar informações sobre o indicador da Inserção Social e, assim, contemplar elementos que pudessem ser relevantes no âmbito do Sistema de Avaliação da Pós-Graduação.

Diante do exposto acerca do indicador Inserção Social, compreende-se que a gestão de recursos, em que aqui foram identificados os que se vinculam à gestão de pessoas e à infraestrutura do programa, é crucial para o desempenho do programa na Avaliação, merecendo os recursos serem considerados em termos de estratégias para enfrentar desafios e barreiras encontradas nos ambientes em que o PPGA atua. Pelas falas dos entrevistados, houve a constatação de fragilidades nesse indicador, o qual também era impactado por políticas governamentais na área de fomento ao ensino superior. A seguir, traz-se a síntese das análises realizadas ao longo desta subseção.

\section{Síntese de resultados e sugestões de melhoria}

Nesta subseção faz-se a síntese dos resultados referentes aos indicadores da avaliação da Capes, que foram considerados para se compreender o processo de gestão estratégica do PPGA e identificar aquelas vigentes em seu âmbito, conforme a Figura 2. 


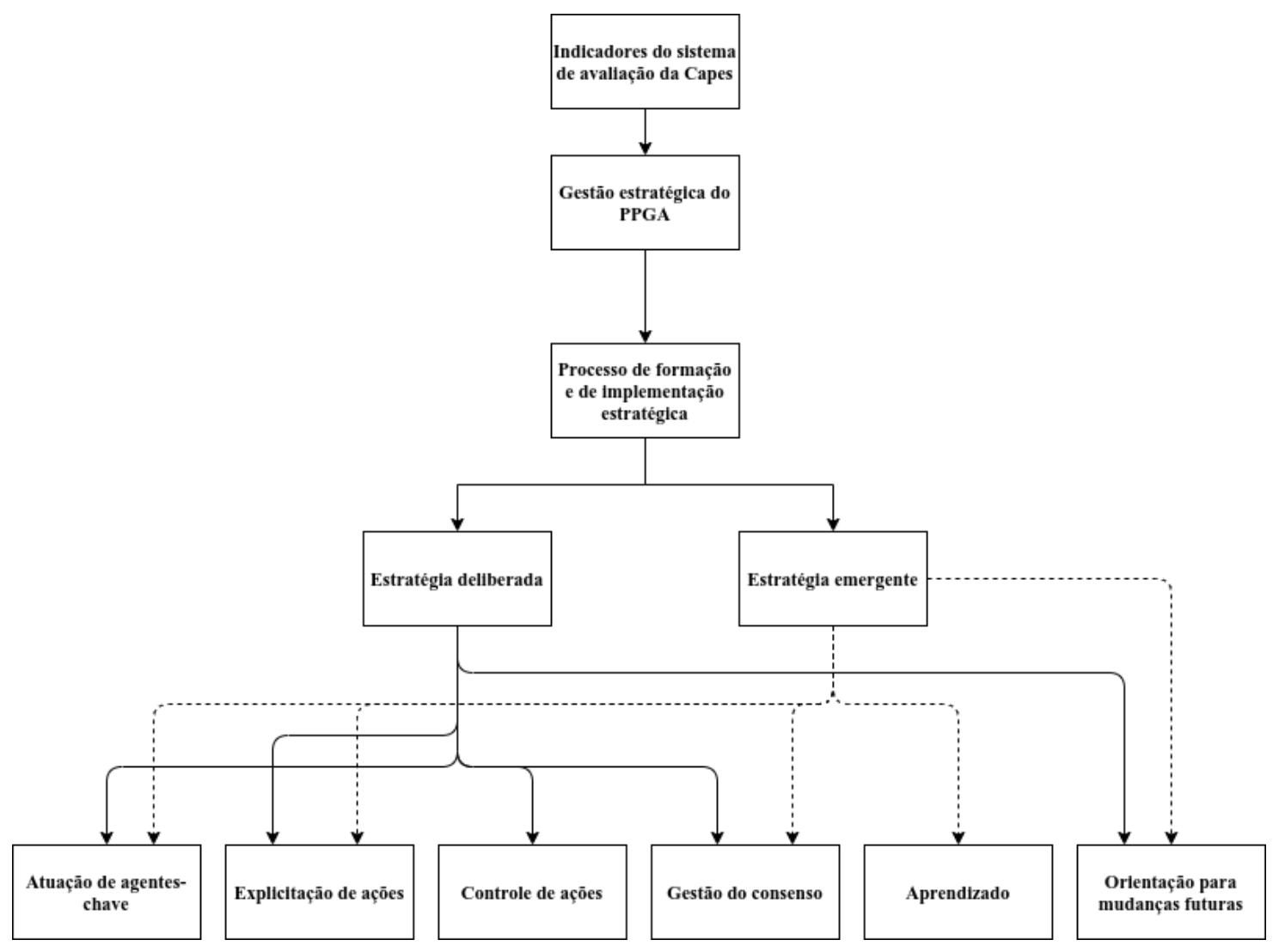

Fonte: Elaboração das autoras (2017).

A Figura 2 apresenta o processo estratégico do PPGA a partir da influência do Sistema de Avaliação da Capes, que se materializa pelos indicadores que foram contemplados nas estratégias deliberadas e também nas emergentes identificadas. Ou seja, pela figura citada, pode-se notar que as dimensões teóricas "Atuação de agentes-chave"; "Explicitação de ações”, “Gestão de consenso" e "Orientação para mudanças futuras" estiveram presentes no processo de formação e de implementação estratégica do PPGA, tanto nas estratégias deliberadas como nas emergentes.

Isso ressalta que os fluxos de informações organizacionais que originam tais dimensões não se limitam a um tipo específico de estratégia. Porém, a dimensão "Controle de ações" esteve presente apenas nas estratégias deliberadas, enquanto a dimensão "Aprendizado" apareceu nas estratégias de natureza emergente.

Dessa maneira, constatada a relevância da gestão estratégica no âmbito do PPGA, ressalta-se que dois indicadores não apresentavam estratégias, quais sejam: Corpo Docente e Inserção Social. Tanto no primeiro como no segundo, verificou-se pelas entrevistas que o trabalho de execução de ações para seu cumprimento ficou majoritariamente sob o encargo dos docentes e de suas ações individuais. Nesse sentido, quanto ao indicador Corpo Docente, devido à sua importância global e em termos de pesos do Sistema de Avaliação, recomenda-se ao programa que busque, 
em nível de gestão, discutir estratégias que o contemplem e, assim, gerenciar o desempenho dos professores para melhorar os resultados do programa.

No que se refere ao indicador Inserção Social, recomenda-se, além de estabelecer um pensamento estratégico voltado aos itens que o compõem, que se procure viabilizar uma maior aproximação aos discentes do programa, para efetivamente conscientizá-los de seu papel no desempenho do PPGA. De tal forma, quando se tornarem egressos, que eles mantenham suas informações atualizadas para facilitar o processo de acompanhamento de suas trajetórias acadêmicas e profissionais e assim colaborar para a mensuração do desempenho do programa em termos de qualidade e repercussão social.

\section{CONSIDERAÇÕES FINAIS}

Neste estudo, buscou-se compreender a temática avaliação da educação superior brasileira alinhada à teoria da estratégia e com ênfase na realidade das universidades, neste caso, especificamente programas de pós-graduação stricto sensu que integram o Sistema Nacional da Pós-Graduação. Para este estudo, foi escolhido o PPGA/UFSC.

Foi possível atender ao objetivo de pesquisa proposto: identificar estratégias para atender ao Sistema de Avaliação da Pós-Graduação brasileira em um programa de pós-graduação em Administração de uma universidade federal, bem como contemplar a proposição teórica do estudo: “O Sistema de Avaliação da PósGraduação brasileira influencia as estratégias dos programas avaliados”.

Isso ocorreu mediante a constatação de que o programa se utilizou de estratégias em seu processo de gestão, as quais eram de natureza deliberada e emergente, com predominância do segundo tipo. Ademais, as ações inerentes a elas alinharam-se às dimensões teóricas relacionadas ao processo de gestão estratégica descritas na literatura abordada no estudo. Tal fato também reforça as afirmações de autores de que o modelo de gestão estratégica para as universidades é um potencial aliado na contribuição para que essas instituições se preparem para o enfrentamento de desafios em seu ambiente de atuação.

O estudo realizado demonstrou, ainda, a maneira como o processo de formação e de implementação estratégica transcorreu durante a vigência das estratégias identificadas no PPGA, em meio a pressão coercitiva exercida pelo Sistema de Avaliação da Capes sobre o processo de gestão do programa. Diante da necessidade de atendimento ao Sistema de Avaliação da Capes e das fragilidades identificadas em relação aos indicadores Corpo Docente e Inserção Social, foram propostas melhorias, de modo que os integrantes do programa pudessem dialogar e se apropriar ainda mais da gestão estratégica como forma de sanar tais problemas. 
Em termos de limitações, tem-se que a pesquisa abordou a visão da gestão do programa sobre o fenômeno de interesse. Portanto, ao estabelecer o foco nesse grupo de entrevistados, não foram pesquisadas as percepções de outros atores sociais que coproduzem o processo de gestão estratégica, a exemplo de estudantes, equipe de apoio administrativo e de docentes que integram programas de pós-graduação.

Para estudos futuros, diante do impacto do Sistema de Avaliação da Capes na gestão dos programas de pós-graduação brasileiros nele avaliados, é relevante ampliar os grupos de atores sociais a serem pesquisados, bem como considerar o aprofundamento acerca das pressões que tal sistema exerce, sob que lógica ele opera e sobre como tais programas podem desenvolver uma gestão estratégica efetiva para atender também a outros stakeholders.

Dentre eles podem-se mencionar os órgãos governamentais que elaboram políticas de desenvolvimento econômico e de inovação, outras agências públicas, ou não, de fomento à pesquisa, dado o caráter estratégico que o conhecimento produzido no nível stricto sensu desempenha para os sistemas regionais e nacionais de inovação. Soma-se a isso o impacto social da pós-graduação nas searas de formação de profissionais para o mercado de trabalho, para a difusão e compartilhamento de expertises entre entidades nacionais que dialogam com a academia, tais como as associações profissionais e de pesquisa, entre outras.

Por fim, essa conjuntura de interação pode, ainda, ser pensada em termos de estratégias que se voltam para um contexto de internacionalização da pós-graduação, que abrange o diálogo entre instituições científicas ao redor do globo e realidades de nações que apresentam aspectos semelhantes a respeito da formação de nível superior e de desenvolvimento social.

\section{REFERÊNCIAS}

ANDERSEN, T. J. Strategic planning, autonomous actions and corporate performance. Long Range Planning, v. 33, n. 2, p. 184-200, 2000.

ANDERSEN, T. J. Integrating the strategy formation process: an international perspective. European Management Journal, v. 22, n. 3, p. 263-272, 2004.

ANDERSEN, T. J. Short introduction to strategic management. Cambridge: Cambridge University Press, 2013.

ANGELO, C. Brazil’s scientists fight funding freeze. Nature, v. 539, p. 480, 2016.

ANSOFF, H. I. Corporate strategy: an analytic approach to business policy for growth and expansion. New York: McGraw-Hill Companies, 1965.

BABBIE, E. The practice of social research. 8. ed. Wadsworh, USA: Publishing Company, 1998. 
BALBASTRE-BENAVENT, F.; CANET-GINER, M. T. The strategy formation process in the EFQM excellence model: a critical review and new perspectives. Total Quality Management and Business Excellence, v. 22, n. 7, p. 727-742, 2011.

BARDIN, L. Análise de conteúdo. São Paulo: Edições 70, 2011.

BARNARD, C. I. The functions of the executive. Cambridge, MA: Harvard Universty Printing Office, 1938.

BARNES, D. The complexities of the manufacturing strategy formation process in practice. International Journal of Operations and Production Management, v. 22, n. 9-10, p. 1090-1111, 2002.

BHALLA, A.; LAMPEL, J.; HENDERSON, S.; WATKINS, D. Exploring alternative strategic management paradigms in high-growth ethnic and non-ethnic family firms. Small Business Economics, v. 32, n. 1, p. 77-94, 2009.

BRASIL. Lei n. 9.394, de 20 de dezembro de 1996. Estabelece as diretrizes e bases da educação nacional. Diário Oficial da União, Brasília, DF, 23 dez. 1996. Disponível em: http://www.planalto. gov.br/ccivil_03/Leis/L9394.htm. Acesso em: ago. 2020.

BRASIL. Ministério da Educação. Coordenação de Aperfeiçoamento de Pessoal de Nível Superior. Proposta do programa. Programa de Pós-Graduação em Administração (PPGA/UFSC). Brasília, DF, 2007. Disponível em: https://sucupira.capes.gov.br/sucupira/public/consultas/coleta/ propostaPrograma/listaProposta.jsf. Acesso em: 18 ago. 2017.

BRASIL. Ministério da Educação. Coordenação de Aperfeiçoamento de Pessoal de Nível Superior. História e missão. Brasília, DF: Capes, 17 jun. 2008. Disponível em: http://www.capes.gov.br/ historia-e-missao. Acesso em: 20 dez. 2016.

BRASIL. Ministério da Educação. Coordenação de Aperfeiçoamento de Pessoal de Nível Superior. Plano Nacional de Pós-Graduação (PNPG) 2011-2020: documentos setoriais. Brasília, DF: Capes, 2010. v. II. Disponível em: http://www.capes.gov.br/sobre-a-capes/plano-nacional-de-pos-graduacao/ pnpg-2011-2020. Acesso em: 18 mar. 2017.

BRASIL. Ministério da Educação. Coordenação de Aperfeiçoamento de Pessoal de Nível Superior. Programa de Pós-Graduação em Administração UFSC: proposta programa relatório 2015. Brasília, DF: Capes, 2015. Disponível em: https://sucupira.capes.gov.br/sucupira/public/consultas/coleta/ propostaPrograma/listaProposta.jsf\%3E. Acesso em: $10 \mathrm{dez} .2016$.

BRASIL. Ministério da Educação. Coordenação de Aperfeiçoamento de Pessoal de Nível Superior. Sobre a avaliação. Brasília, DF: Capes, 2016a. Disponível em: http://www.capes.gov.br/avaliacao/ sobre-a-avaliacao. Acesso em: 8 dez. 2016.

BRASIL. Ministério da Educação. Coordenação de Aperfeiçoamento de Pessoal de Nível Superior. Documento de área: Administração Pública e de Empresas, Ciências Contábeis e Turismo. Brasília, DF: Capes, 2016b. Disponível em: http://www.capes.gov.br/component/content/article/44avaliacao/4649-administracao-ciencias-contabeis-e-turismo. Acesso em: 15 mar. 2017.

BRASIL. Ministério da Educação. Coordenação de Aperfeiçoamento de Pessoal de Nível Superior. Relatório de dados enviados da coleta - 2015. Programa de Pós-Graduação em Administração (PPGA/ UFSC). Brasília, DF: Capes, 2016c.

BRASIL. Ministério da Educação. Coordenação de Aperfeiçoamento de Pessoal de Nível Superior. Módulo coleta de dados. Brasília, DF: Capes, 2017a. Disponível em: http://www.capes.gov.br/ avaliacao/plataforma-sucupira/modulo-coleta-de-dados. Acesso em: 13 jun. 2017. 
BRASIL. Ministério da Educação. Coordenação de Aperfeiçoamento de Pessoal de Nível Superior. Qualis Periódicos. Brasília, DF: Capes, 2017b. Disponível em: https://sucupira.capes.gov.br/sucupira/ public/consultas/coleta/veiculoPublicacaoQualis/listaConsultaGeralPeriodicos.jsf. Acesso em: 4 ago. 2018.

BULGACOV, S.; SOUZA, Q. R.; PROHMANN, J. D. P.; COSER, C.; BARANIUK, J. Administração estratégica: teoria e prática. São Paulo: Atlas, 2007.

CHANDLER, A. D. Strategy and structure: chapters in the history of the industrial enterprise. Massachusetts: MIT Press, 1962. v. 120.

COHEN, M. D.; MARCH, J. G.; OLSEN, J. P. A garbage can model of organizational choice. Administrative Science Quarterly, v. 17, n. 1, p. 1-25, 1972.

CORRÊA, C. P.; RODRIGUES, L. M. A.; FIATES, G. G. S.; MARTINS, C. B. Estudo bibliométrico sobre o Sistema de Avaliação da Pós-Graduação Brasileira. In: ENCONTRO DA ASSOCIAÇÃO NACIONAL DE PÓS-GRADUAÇÃO E PESQUISA EM ADMINISTRAÇÃO, 41., 2017, São Paulo. Anais [...]. São Paulo: Associação Nacional de Pós-Graduação e Pesquisa em Administração, 2017. Disponível em: http://www.anpad.org.br/ anpad/eventos.php?cod_evento=1\&cod_evento_ edicao=89\&cod_edicao_subsecao=1453. Acesso em: 13. jun. 2017.

EASTERBY-SMITH, M. Change and innovation in higher education: a role for corporate strategy? Higher Education, v. 16, n. 1, p. 37-52, 1987.

ELBANNA, S. Strategic decision making: process perspectives. International Journal of Management Reviews, v. 8, n. 1, p. 1-20, 2006.

FAGÁ, I. T.; QUONIAM, L. M. A relação entre produção científica e avaliação da Capes: um estudo cientométrico de um programa das engenharias II e de um programa interdisciplinar. Revista Brasileira de Pós-Graduação, Brasília, v. 12, n. 29, p. 651-679, 2015.

FARJOUN, M. Towards an organic perspective on strategy. Strategic Management Journal, v. 23, p. 561-594, 2002.

FLOYD, S. W.; WOOLDRIDGE, B. Management's strategic influence. Journal of Management Studies, v. 34, n. 3, p. 465-485, 1997.

FUENTES, S. G. El crecimiento de los posgrados en educación en Argentina. Notas acerca de la estructura de la oferta y las políticas de evaluación. Avaliação: Revista da Avaliação da Educação Superior, Campinas, SP, v. 21, n. 3, p. 859-900, 2016.

GOUVÊA, F. C. F. A institucionalização da pós-graduação no Brasil: o primeiro decênio da Capes (1951-1961). Revista Brasileira de Pós-Graduação, Brasília, v. 9, n. 17, p. 373-397, 2012.

HART, S. L. An Integrative framework for strategy-making processes. The Academy Of Management Review, v. 17, n. 2, p. 327-351, 1992.

HAX, A. C.; MAJLUF, N. S. The concept of strategy and the strategy formation process. Interfaces, Guarapuava, PR, v. 18, n. 3, p. 99-109, 1988.

HENSMANS, M. Social movement organizations: a metaphor for strategic actors in institutional fields. Organization Studies, v. 24, n. 3, p. 355-381, 2003. 
HOUSE, E. R. Tendencias en evaluación. Revista de Educación, v. 299, n. 1, p. 43-55, 1992.

JARZABKOWSKI, P. Strategy as practice. London: Sage Publications, 2005.

JOHNSON, G.; SCHOLES, K.; WHITTINGTON, R. Exploring corporate strategy: text and cases. 7. ed. London: Pearson Education Limited, 2005.

KHANAGHA, S.; VOLBERDA, H.; OSHRI, I. Business model renewal and ambidexterity: structural alteration and strategy formation process during transition to a cloud business model. $R$ and $D$ Management, v. 44, n. 3, p. 322-340, 2014.

KIM, Y. H.; STING, F. J.; LOCH, C. H. Top-down, bottom-up, or both? Toward an integrative perspective on operations strategy formation. Journal of Operations Management, v. 32, n. 7-8, p. 462-474, 2014.

KOTLER, P.; BERGER, R.; BICKHOFF, N. The quintessence of strategic management: what you really need to know to survive in business. Heidelberg: Springer, 2010.

LAVARDA, R. A. B.; GINER, M. T. C.; BONET, F. J. P. Understanding how the strategy formation process interacts with the management of complex work. European Business Review, v. 23, n. 1, p. 71-86, 2011.

LINDSAY, A. Assessing institutional performance in higher education: a managerial perspective. Higher Education, v. 10, n. 6, p. 687-706, 1981.

LUECKE, R. Estratégia. Rio de Janeiro: Record, 2009.

MACCARI, E. A.; ALMEIDA, M. I. R. D.; NISHIMURA, T. A.; RODRIGUES, L. C. A gestão dos programas de pós-graduação em administração com base no sistema de avaliação da Capes. Revista de Gestão USP, São Paulo, v. 16, n. 4, p. 1-16, 2009.

MACCARI, E. A.; ALMEIDA, M. I. R. D.; RICCIO, L. E.; ALEJANDRO, T. B. Proposta de um modelo de gestão de programas de pós-graduação na área de Administração a partir dos sistemas de avaliação do Brasil (Capes) e dos Estados Unidos (AACSB). Revista de Administração, São Paulo, v. 49, n. 2, p. 369-383, 2014.

MACCARI, E. A.; GOMES JUNIOR, J. C.; KNIESS, C. T.; BIANCOLINO, C. A. Levantamento de requisitos para a proposta de um aplicativo para acompanhamento dos quesitos do Sistema de Avaliação da Capes. Revista de Gestão Universitária na América Latina, Florianópolis, v. 8, n. 3, p. 1-25, 2015.

MACCARI, E. A.; MARTINS, C. B.; ALMEIDA, M. I. R. de. Comparativo entre os sistemas de avaliação da Association to Advance Collegiate Schools of Business (Estados Unidos) e da Coordenação de Aperfeiçoamento de Pessoal de Nível Superior (Brasil) e o seu uso pelos coordenadores de programas. Revista Brasileira de Pós-Graduação, Brasília, v. 12, n. 27, p. 39-66, 2015.

MACCARI, E. A.; NISHIMURA, A. T. Povoamento dos estratos conceitos 6 e 7 no sistema de avaliação da Capes pela área de administração, ciências contábeis e turismo nas avaliações trienais 2010 e 2013. Revista Eletrônica de Administração, Porto Alegre, v. 79, n. 3, p. 601-624, 2014.

MACHADO-DA-SILVA, C. L. Respostas estratégicas da administração e contabilidade ao sistema de avaliação da Capes. Organizações \& Sociedade, Salvador, v. 10, n. 28, p. 63-82, 2003. 
MAGGI, M. T.; PAREDES, M. C. The role of relevance in the evaluation of university programs in Ecuador. Revista Ciencias Pedagógicas e Innovación, v. 5, n. 3, p. 1-9, 2017.

MAINARDES, E. W.; FERREIRA, J. J. de M.; TONTINI, G. O entendimento do conceito de estratégia e de gestão estratégica dos formandos em administração. Revista ANGRAD, Rio de Janeiro, v. 10, n. 4 , p. 55-82, 2009.

MARCHELLI, P. S. O sistema de avaliação externa dos padrões de qualidade da educação superior no Brasil: considerações sobre os indicadores. Estudos em Avaliação Educacional, São Paulo, v. 18, n. 37, p. 189-216, 2007.

MARCONI, M. A. de; LAKATOS, E. M. Metodologia científica. 5. ed. São Paulo: Atlas, 2010.

MARCONI, M. A. de; LAKATOS, E. M. Ténicas de pesquisa. São Paulo: Atlas, 2015.

MARENCO, A. When institutions matter: capes and political science in Brazil. Revista de Ciência Política, São Paulo, v. 35, n. 1, p. 33-46, 2015.

MARTINS, C. B.; MACCARI, E. A. Desempenho dos programas de pós-graduação stricto sensu em administração, ciências contábeis e turismo no Brasil. Jundiaí, SP: Paco Editorial, 2015.

MARTINS, C. B.; MACCARI, A. E.; STOROPOLI, E. J.; ALMEIDA, M. I. R. D. A influência do sistema de avaliação nos programas de pós-graduação stricto sensu brasileiro. Revista Gestão Universitária na América Latina, Florianópolis, v. 5, n. 3, p. 155-178, 2012.

MASSEN, P. A. M.; POTMAN, H. P. Strategic decision making in higher education an analysis of the new planning system in dutch higher education. Higher Education, v. 20, p. 393-410, 1990.

MEYER JÚNIOR, V. M.; LOPES, M. C. B. Administrando o imensurável: uma crítica às organizações acadêmicas. Cadernos EBAPE.BR, Rio de Janeiro, v. 13, n. 1, p. 40-51, 2015.

MINTZBERG, H. The strategy concept I: five Ps for strategy. California Management Review, v. 30, n. 1, p. 11-24, 1987.

MINTZBERG, H.; AHLSTRAND, B.; LAMPEL, J. Strategy safari: a guided tour through the wilds of strategic management. New York: Bookman, 1998.

MINTZBERG, H.; LAMPEL, J. Reflecting on the Strategy Process. Sloan management review, v. 40, n. 3, p. 21-30, 1999.

MINTZBERG, H.; QUINN, J. B. Readings in strategy process. Upper Saddle River, NJ: Prentice Hall Inc., 1998.

MINTZBERG, H.; QUINN, J. B. o processo da estratégia. 3. ed. Porto Alegre: Bookman, 2001.

MINTZBERG, H.; WATERS, J. A. Of strategies, deliberate and emergent. Strategic Management Journal, v. 6, n. 3, p. 257-272, 1985.

MORITZ, G. D. O.; MORITZ, M. O.; MELO, P. A. de. A pós-graduação brasileira: evolução e principais desafios no ambiente de cenários prospectivos. In: COLÓQUIO INTERNACIONAL SOBRE GESTÃO UNIVERSITÁRIA NA AMÉRICA DO SUL, 11.; CONGRESSO INTERNACIONAL IGLU, 2., 2011, Florianópolis. Anais [...]. Florianópolis, 2011. p. 1-18.

NONAKA, I. Toward middle-up-down management: accelerating information creation. Sloan Management Review, v. 29, n. 3, p. 9-18, 1988. 
OLIVEIRA, M. R.; ALMEIDA, J. Programas de pós-graduação interdisciplinares - contexto, contradições e limites do processo de avaliação Capes. Revista Brasileira de Pós-Graduação, Brasília, v. 8, n. 15, p. 37-57, 2011.

OVERED, R. So what is strategy? Long Range Planning, v. 16, n. 3, p. 57-72, 1983.

PETTIGREW, A. M. The character and significance of strategy process research. Strategic Management Journal, v. 13, n. S2, p. 5-16, 1992.

PORTER, M. E. Competitive strategy: techniques for analyzing industries and competitors. New York: The Free Press, 1980.

PORTER, M. E. The five competitive forces that shape strategy. Harvard Business Review, v. 86, n. January, p. 78-94, 2008.

QEHAJA, A. B.; KUTLLOVCI, E.; PULA, J. S. Strategic management tools and techniques usage: a qualitative review. Acta Universitatis Agriculturae et Silviculturae Mendelianae Brunensis, v. 65, n. 2, p. 585-600, 2017.

QUINN, J. Strategic change: “logical incrementalism”. Sloan Management Review, v. 20, n. 1, p. 7-21, 1978.

RIALP-CRIADO, A.; GALVÁN-SÁNCHEZ, I.; SUÁREZ-ORTEGA, S. M. A configuration-holistic approach to born-global firms' strategy formation process. European Management Journal, v. 28, n. 2, p. 108-123, 2010.

RING, P. S.; DOZ, Y. L.; OLK, P. M. Managing Formation Processes in R\&D Consortia. California Management Review, v. 47, n. 4, p. 137-156, 2005.

RIZZATTI, G.; RIZZATTI JUNIOR, G. Organização universitária: mudanças na administração e nas funções administrativas. In: COLÓQUIO INTERNACIONAL SOBRE GESTÃO UNIVERSITÁRIA NA AMÉRICA DO SUL, 4., 2004, Florianópolis. Anais [...]. Florianópolis: Universidade Federal de Santa Catarina, 2004.

ROESCH, M. S. A. Projetos de estágio e de pesquisa em administração: guia para estágios, trabalhos de conclusão, dissertações e estudos de caso. São Paulo: Atlas, 2009.

RONDA-PUPO, G. A.; GUERRAS-MARTIN, L. A. Dynamic of the evolution of the strategy concept 1962-2008: a co-word analysis. Strategic Management Journal, v. 33, p. 162-188, 2012.

SAUNDERS, M.; LEWIS, P.; THORNHILL, A. Research methods for business students. 5. ed. New York: Prentice Hall Inc., 2009.

SHIGAKI, H. B.; PATRUS, R. O papel da produção intelectual no Sistema de Avaliação dos Programas de Administração pela Capes. Teoria e Prática em Administração, João Pessoa, v. 2, n. 2, p. 126-150, 2012.

SMINIA, H. Process research in strategy formation: Theory, methodology and relevance. International Journal of Management Reviews, v. 11, n. 1, p. 97-125, 2009.

TEIXEIRA, G. C. S. dos S.; MACCARI, E. A.; MARTINS, C. B. Influência da regulamentação da coordenação de aperfeiçoamento de pessoal de nível superior (Capes) na gestão estratégica de projetos educacionais. Revista Gestão \& Tecnologia, Pedro Leopoldo, MG, v. 16, n. 2, p. 238-259, 2016. 
UNIVERSIDADE FEDERAL DE SANTA CATARINA - UFSC. Resolução n. 40, de 14 de fevereiro de 2011. Aprova o regimento interno do programa de pós-graduação em administração. Boletim Oficial da Universidade Federal de Santa Catarina, Florianópolis, 2011.

UNIVERSIDADE FEDERAL DE SANTA CATARINA - UFSC. Programa de Pós-Graduação em Administração. Resolução n. 1, de 30 de junho de 2015. Dispõe sobre o credenciamento de docentes no Programa de Pós-Graduação em Administração. Florianópolis: Programa de Pós-Graduação em Administração da Universidade Federal de Santa Catarina, 30 jun. 2015. Disponível em: http://ppgadm.posgrad.ufsc.br/files/2014/06/Resolução-01PPGA2015-Credenciamento.pdf. Acesso em: 19 fev. 2017.

UNIVERSIDADE FEDERAL DE SANTA CATARINA - UFSC. Programa de Pós-Graduação em Administração: Quantitativos. Florianópolis: Universidade Federal de Santa Catarina, 2017. Disponível em: http://ppgadm.posgrad.ufsc.br/. Acesso em: 12 nov. 2017.

VAN DAMME, D. Internationalization and quality assurance: towards worldwide accreditation? European Journal for Education Law and Policy, v. 4, n. 1, p. 1-20, 2000.

VERGARA, S. C. Projetos e relatórios de pesquisa em administração. São Paulo: Atlas, 2007.

VERHINE, R. E.; DANTAS, L. M. V. Reflexões sobre o sistema de avaliação da Capes a partir do V Plano Nacional de Pós-Graduação. Revista de Educação Pública, Cuiabá, v. 18, n. 37, p. 295-310, 2009.

VILLANUEVA, E. La acreditación en américa latina: el caso de Argentina en la riaces y el Mercosur. Revista Iberoamericana de Educación, n. 35, p. 99-112, 2004.

VOGEL, M. J. M.; KOBASHI, N. Y. Avaliação da pós-graduação no Brasil: seus critérios. In: ENANCIB - ENCONTRO NACIONAL DE PESQUISA EM CIÊNCIA DA INFORMAÇÃO, 16., 2015, João Pessoa. Anais [...]. João Pessoa, 2015. p. 2-18.

VOLBERDA, H. W. Crisis in strategy: fragmentation, integration or synthesis. European Management Review, v. 1, n. 1, p. 35-42, 2004.

WALKER, R. M. Strategic management and performance in public organizations: Findings from the miles and snow framework. Public Administration Review, v. 73, n. 5, p. 675-685, 2013.

WHITTINGTON, R. Strategy as Practice Mapping the Terrain. Long Range Planning, v. 29, n. 5, p. 731-735, 1996.

WHITTINGTON, R. O que é estratégia. São Paulo: Thomson, 2002.

Recebido em: 14 MAIO 2019

Aprovado para publicação em: 4 SETEMBRO 2020 